\title{
MICROSTRUCTURES AND PHYSICAL PROPERTIES OF BIOMORPHIC SISIC CERAMICS MANUFACTURED VIA LSI-TECHNIQUE
}

\author{
Steffen Weber, Raouf Jemmali, Dietmar Koch and Heinz Voggenreiter \\ Department of Ceramic Composite and Structures, Institute of Structures and Design \\ German Aerospace Center, Stuttgart, Germany
}

\begin{abstract}
Biomorphic SiSiC ceramic composites were produced by liquid silicon infiltration (LSI) process. These materials are based on activated coal (ACBC) and wood fibers (MDF). Microstructural characteristics in green-, carbon- and SiSiC-body modification were investigated by analyzing curved structures (type charcoal) and planar structures (type MDF). Therefore polished and unpolished specimens have been examined with scanning electron microscopy (SEM), microfocus X-ray computed tomography (CT) and respective evaluation software. Focused on the objective of near net shape reproducibility for the ceramic composites, different shrinkage and silicon uptake behavior were identified. Furthermore, significant capillarities, densities and porosities could be determined and valued regarding the objective and highest possible SiC content. The appearing different SiSiC microstructures influence the physical properties of SiSiC ceramics such as flexural strength, Young's modulus and hardness, which were detected with standardized testing methods.
\end{abstract}

\section{INTRODUCTION}

New innovated materials based on biogenic raw materials are becoming increasingly important in applied CMC technology. Biomorphic SiSiC ceramics, produced by liquid silicon infiltration process (LSI) ${ }^{[1,2]}$, offer an alternative to commercial sintered silicon carbide ceramics. Consequently, the use of expensive ceramic powders or granulates and also the necessary high energy level by sintering can be avoided. Due to the high stiffness as well as hardness, good corrosion and temperature resistance biomorphic SiSiC ceramics provides an opportunity in the application sectors energy technology, commercial mechanical engineering and ballistic protection. ${ }^{[3-8]}$ Thereby, manufacture of complex shaped structures with application-specific microstructural properties become the focus of development. In addition, the possibility of near net-shape production of complex shaped SiSiC structures marks a further key factor for economic use in various applications. ${ }^{[9,10]}$ In this context, shrinkage is a problem of wood based biomorphic materials during liquid silicon infiltration process steps. However, activated coal based compounds offer strongly reduced shrinkage and therefore net shape manufacturing of complex shaped ceramic structures. Furthermore, variable shaping options arising from the use of warm pressing process step in the early beginning of LSI-process.

The aim of this paper was the analysis of basic physical properties and generating more information about the configurations and their characteristics after significant processing steps in LSIroute of biomorphic SiSiC ceramics based on activated coal and wood fibers. These investigations were focused on the characterization of pore channel systems and microstructures. In addition, first information about processing curved structures by powdery compounds via warm pressing and subsequent silicon infiltration could be provided.

\section{EXPERIMENTAL PROCEDURE}

\section{Material composition and manufacture}

The produced and investigated biomorphic SiSiC ceramics are based on different raw material composition. A distinction is made in wood ceramic type MDF, results from commercially available medium density fiberboard and ceramics based on activated carbon type ACBC. In the case of ACBC ceramics a phenolic resin is used as a binder and additional carbon source. Two activated carbon 
variants with different surface characteristics were used. As a further extension, two material grades are reinforced with carbon fibers. The compounds based on carbon were produced by mixing and simultaneously homogenizing of the raw materials. Finally four material variants were produced. The various configurations are given in table I.

Table I. Composition of material variants.

\begin{tabular}{ccccccc}
\hline \hline Material & \multicolumn{5}{c}{ Composition [vol.\%] } \\
\cline { 2 - 7 } & $\begin{array}{c}\text { Resin } \\
\text { Urea-formaldehyde } \\
\text { + additives }\end{array}$ & Phenolic & Type A & Type B & Carbon fibers & Wood fibers \\
\cline { 2 - 7 } MDF & 15 & - & - & - & - & 85 \\
ACBC-C2 & - & 30 & - & 70 & - & - \\
ACBC-E2 & - & 18 & - & 69 & 13 & - \\
ACBC-E7 & - & 18 & 69 & - & 13 & - \\
\hline \hline
\end{tabular}

The manufacture of biomorphic SiSiC ceramics is a three-stage process, divided into following practical parts. The process steps, which based on each other, are shown schematically in figure 1.

1. Green-body manufacture

The powdery ACBC compounds were transferred into form-stable and near net shape preform structures by using warm pressing procedure. In present work, all three ACBC green bodies were pressed in a planar steel die (reference samples) and additionally in a bowl shaped aluminum die (curved samples), at pressures up to $30 \mathrm{MPa}$ and temperatures up to $200{ }^{\circ} \mathrm{C}$.

The warm pressing process program, which regulates temperature curve and pressurization, was standardized. During filling the die a homogenous distribution of the compounds is essential to ensure a uniform microstructure and dimensional stability of preform.

Commercially available medium density fiberboards represent the plane green body preform of the material variant MDF. Due to the fact, first processing step of green body manufacture is omitted for material type MDF

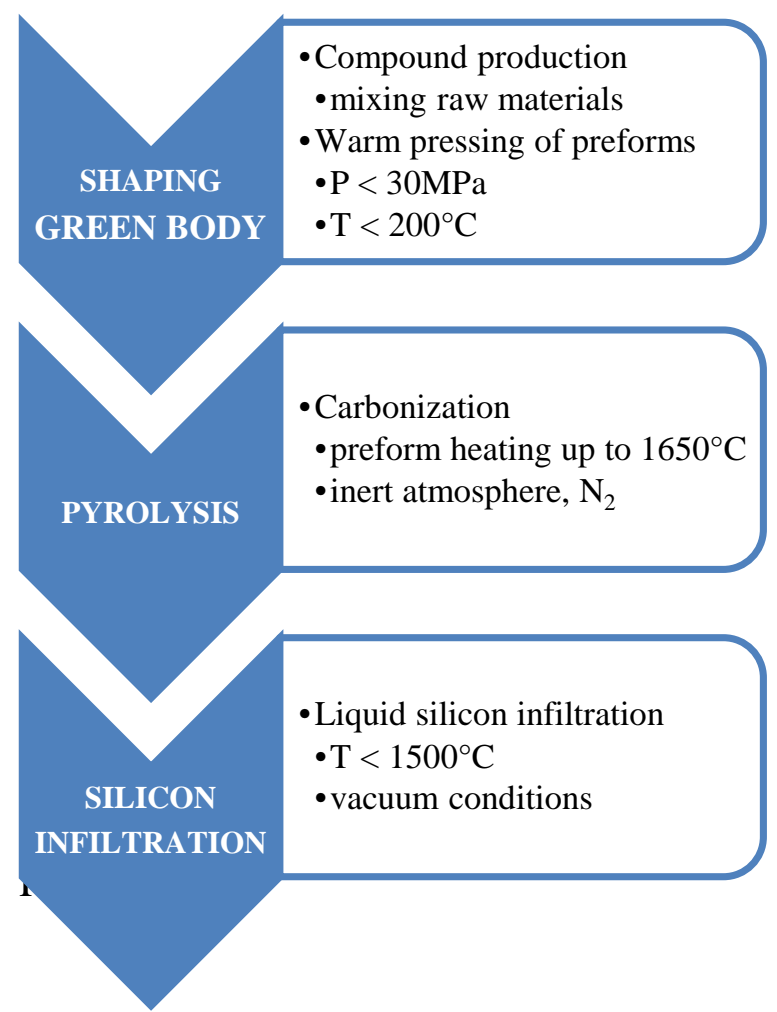

Figure 1. Schematic LSI-process depiction.

\section{Pyrolysis / carbon preform manufacture}

A full conversion of green body to porous carbon preform could be realized with the pyrolysis process step. Thereby, all specimens were heated up to $1650{ }^{\circ} \mathrm{C}$ in a flowing nitrogen atmosphere. This inert atmosphere ensured to remove all fission products and the complete conversion of polymer content to carbon. A furnace (type: OPUS 900, FCT Anlagenbau, Sonneberg, Germany) equipped 
with a carbon retort was used. During this process, mass loss arise with a corresponding volumetric shrinkage, which is critical regarding to near net shape manufacturability of complex formed structural components. All material variants were pyrolysed under the same conditions.

\section{Siliconization}

Finally, the highly porous carbon preforms were infiltrated with liquid silicon at a temperature of more than $1450{ }^{\circ} \mathrm{C}$. This procedure is pressureless and passes by capillary forces. Every sample was infiltrated with sufficient silicon to ensure that the pore channel system is filled completely. The flowing silicon reacts with the carbon capillary walls and forms silicon carbide. After infiltration a biomorphic SiSiC structure with monolith character exists.

\section{Specimen manufacture}

Planar reference plates with dimension $300 \times 300 \times 10 \mathrm{~mm}^{3}$ were produced of each material variant. Green body processing parameters were always the same by manufacturing the ACBC material reference plates. Processing type MDF starts with drying the MDF plates and following pyrolysis step. At the end of LSI process chain, successively parts of the planar plates have been conserved for investigations. All specimens for determination of physical properties were taken from these planar reference plates. Additionally, curved specimens $\left(100 \times 100 \times 4 \mathrm{~mm}^{3}\right.$, curvature radius $\mathrm{R}=97 \mathrm{~mm}$ ) of ACBC material types were manufactured by warm pressing. Finally, resulting curved shaped preforms offered a wide spectrum of compaction degrees in occurring material modifications which deserved closer inspection.

\section{Microstructure characterization}

The microstructures of the materials were investigated after every processing step and thereby in three different microstructure configurations. Density and porosity values by samples of these configurations, could be determined by Archimedes method (according to DIN EN 993-1), pycnometer measuring (type: Accupyc 1330, Micromeritics Instrument Corporation, Norcross, Georgia, USA, acc. to DIN EN 1183), mercury intrusion porosimetry (type: Pascal 240, CE Instruments, Hindley Green, United Kingdom, acc. to DIN EN 66133) and CT investigation.

The determination of open and closed porosity in carbon preforms is an essential parameter for the last process step siliconization. For a sustainable analysis of green body and carbon preform pore channel system, Micro Computer Tomography scans of 12 samples have been performed using a high resolution $\mu \mathrm{CT}$-System consisting of a microfocus $\mathrm{X}$-ray tube with a maximum accelerating voltage of $180 \mathrm{kV}$ and a 12-bit flat panel detector with an active area of 2300x2300 pixels at 50 microns per pixel. The CT specimen size was $4 \times 4 \times 10 \mathrm{~mm}^{3}$. The CT scans have been performed with X-ray parameters of $80 \mathrm{kV} / 200 \mu \mathrm{A}$ and at an exposure time $3000 \mathrm{~ms}$. Pixel size of $1.16 \mu \mathrm{m}$ was attained at this configuration. The acquired X-ray images were reconstructed with a special reconstruction algorithm known as Filtered Back Projection. Each scanned volume was divided into 4 ROIs (Regions of Interest). Consequently, 48 reconstructed data sets had to be evaluated in total. Some image processing techniques such as median filtering were applied to the CT volume images in order to reduce the noise. This step contributed to an increase in the reliability of the image calibration based on gray scale methods. The purpose of the so called calibration or segmentation is to define both material and background allowing for the quantitative analysis of the CT data by evaluating features such as open and closed porosity, inclusions, etc. Due to applying mercury intrusion porosimetry, it was possible to make statements about pore size and pore size distribution of 6 investigated CTspecimens.

Moreover, the use of scanning electron microscope (type: Zeiss Ultra Plus, Carl Zeiss NTS $\mathrm{GmbH}$, Oberkochen, Germany) was served for the detection of 2-dimensional microstructure composition after siliconization. Silicon carbide, residual silicon and carbon level were determined. In 
this context and to evaluate different compaction degrees regarding the silicon carbide conversion, polished and cross sections specimens were prepared out of the curved and planar SiSiC structures.

Shrinkage behavior

A mass- and geometry shrinkage of the structure occurs during pyrolysis because conversion of polymer to carbon. For the investigated materials in this work, the polymer binder consists of phenolic resin (material type $\mathrm{ACBC}$ ) as well as urea-formaldehyde resin (material type MDF). The higher the mass- and volume polymer percentage in preforms, the greater the conversion rate of structure after pyrolysis. To reduce the shrinkage, the materials ACBC E7 and ACBC E2 were spiked with carbon fibers. In this case, anisotropic shrinkage was implied. The shrinkage behavior of all materials during pyrolysis was investigated and compared. For this, cylindrical and plate-shaped green body specimens with different sizes were pyrolysed and statistically evaluated.

\section{Mechanical Testing}

Flexural strength of SiSiC specimens was determined by four-point-bending test at room temperature on a universal testing machine (type: Zwick Roell 1475, according to DIN EN 843-1). One strain gauge on each test sample pull side was used to determine the Young`s modulus. The specimens were $50 \times 4 \times 3 \mathrm{~mm}^{3}$ in length, width and height respectively. A loading rate of $0.5 \mathrm{~mm} \mathrm{~min}^{-1}$ was employed. Fracture surface images of each material were obtained by scanning electron microscopy to reveal the nature and origin of failure under these testing conditions. The Vickers hardness was measured according to DIN EN 6507-1 for the materials under the load of 9.81 Newton (HV1). A correlation between obtained mechanical property values and residual silicon and carbon presence could be made. Furthermore, thermal expansion rates for the temperature range between 20 and $1400{ }^{\circ} \mathrm{C}$ of investigated $\mathrm{SiSiC}$ ceramics were determined by dilatometer measurements (type: DIL 402 C, Netzsch Gerätebau GmbH, Selb, Bayern, Germany, acc. to DIN EN 1159-1).

\section{RESULTS \& DISCUSSION}

\section{Composite microstructures}

Starting with analyzing the planar reference plates, first microstructure information about different material configurations could be collected. Raw density and open porosity measured by Archimedes method and skeleton density measured via heliumpycnometer of specimens cut out from the reference plates were determined. The results are summarized in table II. In context of using the same processing parameters for all plates, the irregular proportionality between decreasing and increasing values of density suggested that differences in carbon modification and pore size distribution must be present. Furthermore, every carbon based material showed different compaction characteristics during warm pressing process. It was more difficult to compact material type E2 than type E7, due to the fact of voluminous carbon grains with size range $20-300 \mu \mathrm{m}$ (activated carbon type B). Carbon type A is more fine-grained with grain sizes between $5-100 \mu \mathrm{m}$. By pressing type C2 without carbon fibers the effect was relativized, which is reflected in green body raw densities. In principle, the skeleton densities approximately were higher by the factor 2 than the raw densities in both high porous configurations green body and carbon preform. High open porosity values in a range of $40-60 \%$ were the basis for silicon infiltration. The resulting SiSiC ceramics showed low open porosities and a good correlation between skeleton and raw density values. Finally, the densities range between $2.7-3.0 \mathrm{~g} / \mathrm{cm}^{3}$, which could be obtained, is very close to pure silicon carbide with a density of approximately $3.2 \mathrm{~g} / \mathrm{cm}^{3}$. 
In relation to carbon preform 450 wt.\% silicon was offered for every type of material during siliconization. The silicon uptake behavior of type MDF was in average $440 \mathrm{wt} . \%$. Considering charcoal materials the silicon uptake was $270 \mathrm{wt}$ \% for type E7, $290 \mathrm{wt} \%$ for type E2 and $215 \mathrm{wt} . \%$ for type C2. Regarding net shape manufacture it would be sufficient to offer $300 \mathrm{wt}$ \% silicon for the ACBC materials under these processing conditions. This adopted amount of silicon would avoid residual silicon on structure surface. Recent SiSiC microstructures of the reference samples are shown in Figure 2. The largest silicon carbide conversion ability was found in type ACBC E7 with 81 vol.\%. Type MDF showed the highest residual silicon content and typical wood fiber derived silicon carbide grains. Cluster of residual carbon (size range $50 \mu \mathrm{m}-200 \mu \mathrm{m}$ ) in microstructure of type C2 indicated differences in pore size distribution compared to fiber reinforced materials. It may be emphasized, that not only the porosity influenced the silicon carbide conversion degree, but also the morphology of the pore channel system.

Table II. Material densities after LSI processing steps.

\begin{tabular}{|c|c|c|c|c|c|c|c|c|c|}
\hline \multirow[t]{3}{*}{ Material } & \multicolumn{3}{|c|}{ Green body configuration } & \multicolumn{3}{|c|}{ Carbon preform } & \multicolumn{3}{|c|}{ SiSiC configuration } \\
\hline & \multicolumn{2}{|c|}{ Density } & \multirow{2}{*}{$\begin{array}{c}\text { Porosity } \\
\text { Open } \\
\text { [\%] } \\
\end{array}$} & \multicolumn{2}{|c|}{ Density } & \multirow{2}{*}{$\begin{array}{c}\text { Porosity } \\
\text { Open } \\
\text { [\%] }\end{array}$} & \multicolumn{2}{|c|}{ Density } & \multirow{2}{*}{$\begin{array}{c}\text { Porosity } \\
\text { Open } \\
\text { [\%] }\end{array}$} \\
\hline & $\begin{array}{r}\text { Skeleton } \\
{\left[\mathrm{g} / \mathrm{cm}^{3}\right]}\end{array}$ & $\begin{array}{c}\text { Raw } \\
{\left[\mathrm{g} / \mathrm{cm}^{3}\right]}\end{array}$ & & $\begin{array}{c}\text { Skeleton } \\
{\left[\mathrm{g} / \mathrm{cm}^{3}\right]}\end{array}$ & $\begin{array}{c}\text { Raw } \\
{\left[\mathrm{g} / \mathrm{cm}^{3}\right]}\end{array}$ & & $\begin{array}{r}\text { Skeleton } \\
{\left[\mathrm{g} / \mathrm{cm}^{3}\right]}\end{array}$ & $\begin{array}{c}\text { Raw } \\
{\left[\mathrm{g} / \mathrm{cm}^{3}\right]}\end{array}$ & \\
\hline MDF & 1.41 & - & - & 1.38 & 0.51 & 62.70 & 2.75 & 2.77 & 0.12 \\
\hline ACBC-C2 & 1.50 & 0.86 & 39.24 & 1.45 & 0.90 & 36.26 & 2.65 & 2.71 & 0.14 \\
\hline ACBC-E2 & 1.62 & 0.80 & 45.16 & 1.51 & 0.76 & 48.40 & 2.95 & 2.96 & 0.14 \\
\hline ACBC-E7 & 1.63 & 0.86 & 46.13 & 1.56 & 0.82 & 46.06 & 3.00 & 3.00 & 0.13 \\
\hline
\end{tabular}
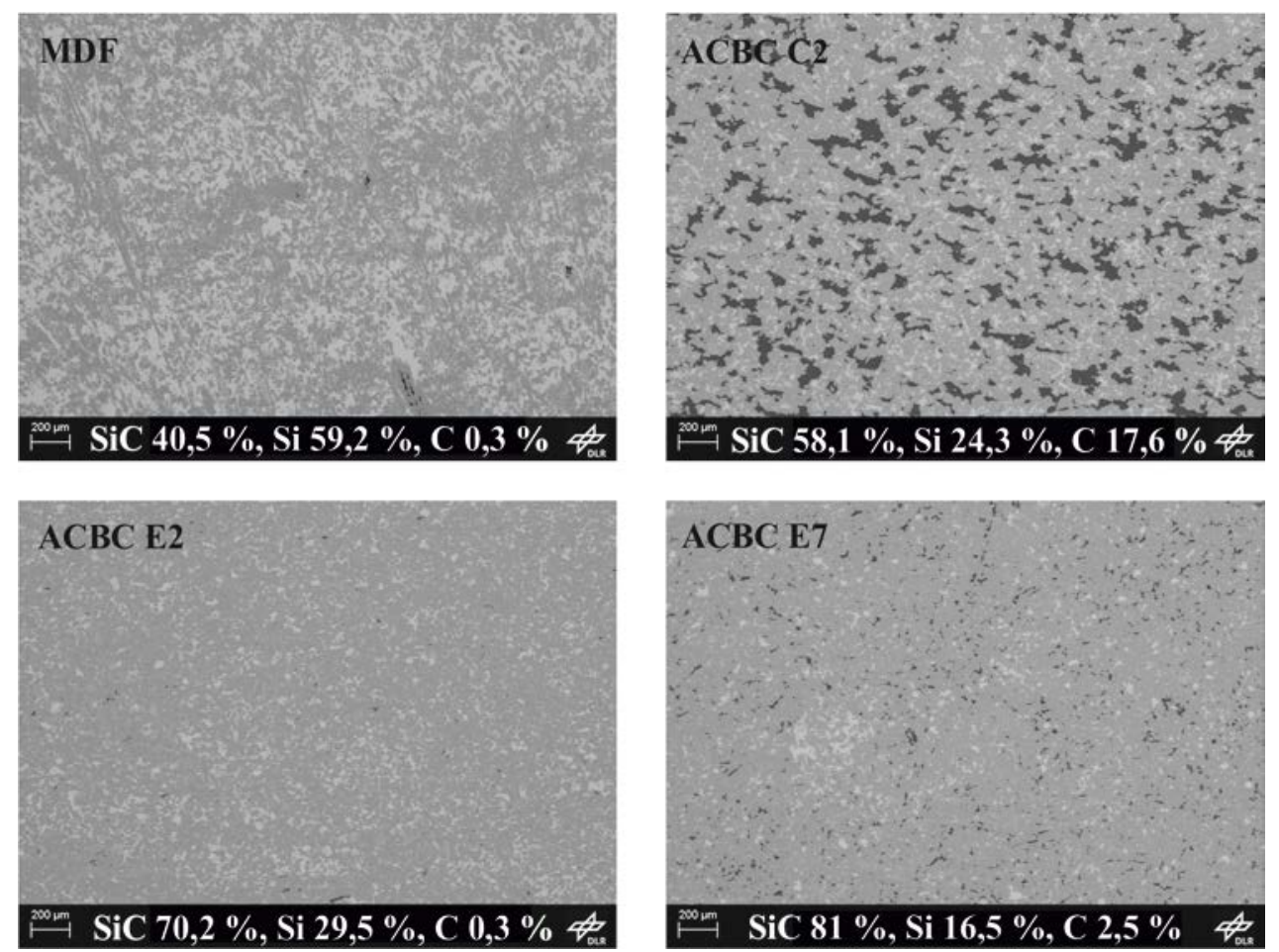

Figure 2. Typical microstructures of SiSiC materials. Black areas represents residual carbon, dark grey areas correspond with silicon carbide and light grey with residual silicon. 
For each ACBC material and its compaction characteristics, different density gradients resulted in curved specimens after warm pressing. For evaluation the raw density and open porosity of every finite sample were measured via Archimedes method. By sampling 3 significant cross section areas a density gradient route was observed. The density gradients in cross section areas of curved specimens and associated specimen sampling description are shown in fig. 3.

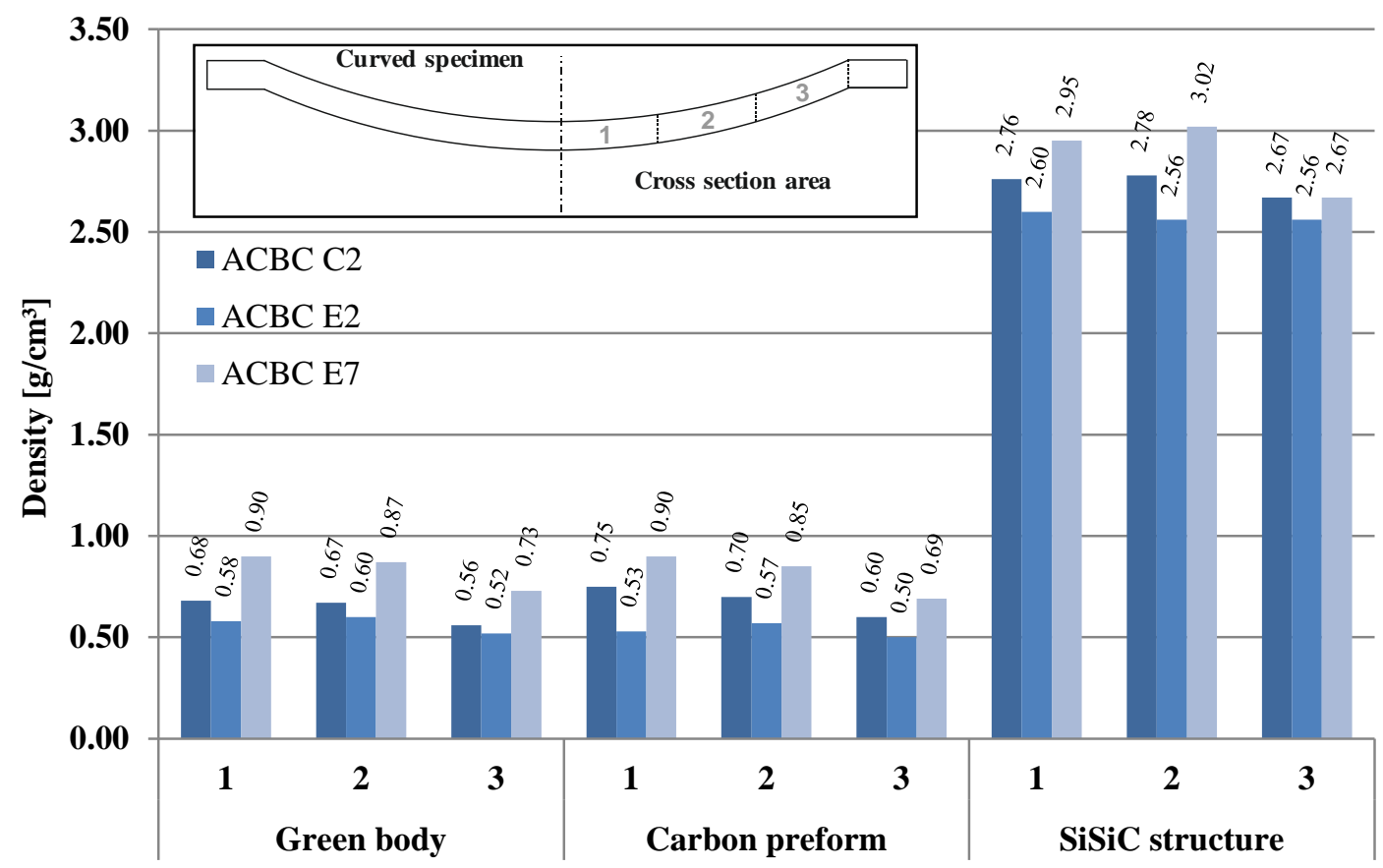

Figure 3. Measured raw density values of curved specimens in all configurations during LSI-route.

After warm pressing, the average density value of type ACBC E7 in green body configuration was nearly the same compared to the plane reference plate. Despite constant processing parameters the types E2 and C2 did not show corresponding density values of reference plates. One reason might be the large grain size of activated carbon type B and its worse compaction characteristics. Furthermore, inhomogeneous compound distribution during filling the curved aluminum die may be another reason for the density gradients in specimen structure.

To extract information about the pore channel system, 2- and 3-dimensional CT images were taken by curved specimens placed in cross section area 1 and 2 for green body and carbon preform configuration. Parts of pore channel system of the samples material C2 (a, b), E2 (c, d) and E7 (e, f) in carbon preform configuration are shown in fig. 4. It might to be reasonably assumed that the carbon fibers reduce the maximum material wall thicknesses. Fundamentally, no significant differences between the carbon fiber containing materials ACBC E2 and E7 and the fiber free material ACBC C2 could be identified. All materials showed a very complex formed channel system with completely connected pore channels and channel branches - in $\mathrm{x}, \mathrm{y}$ and $\mathrm{z}$ orientation. The closed pores as well as foreign inclusions were in a range of $0.1-0.2 \mathrm{vol} . \%$ and therefore very small compared to total investigated volume. Thus, residual carbon in SiSiC configuration based almost exclusively on excess carbon in the walls, which could not be full converted. Open porosities determined by means of CT investigations are slightly smaller than values measured by Archimedes method which might be caused by measuring errors. Beyond this, CT investigations offered only a finite point of view of total volume pore distribution. The results of each investigated finite specimen area are summarized in table III. 

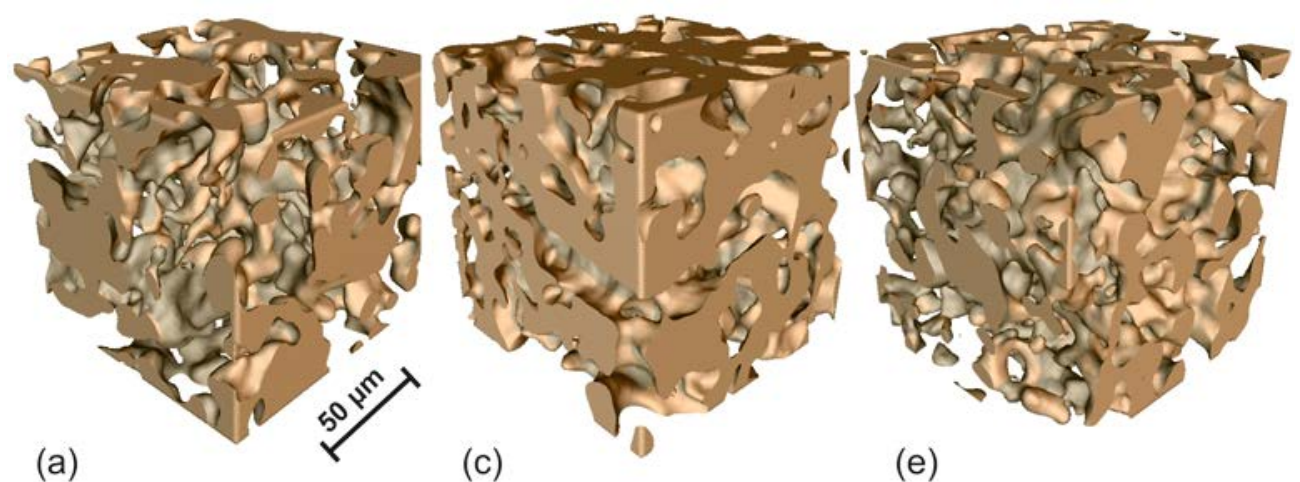

(e)
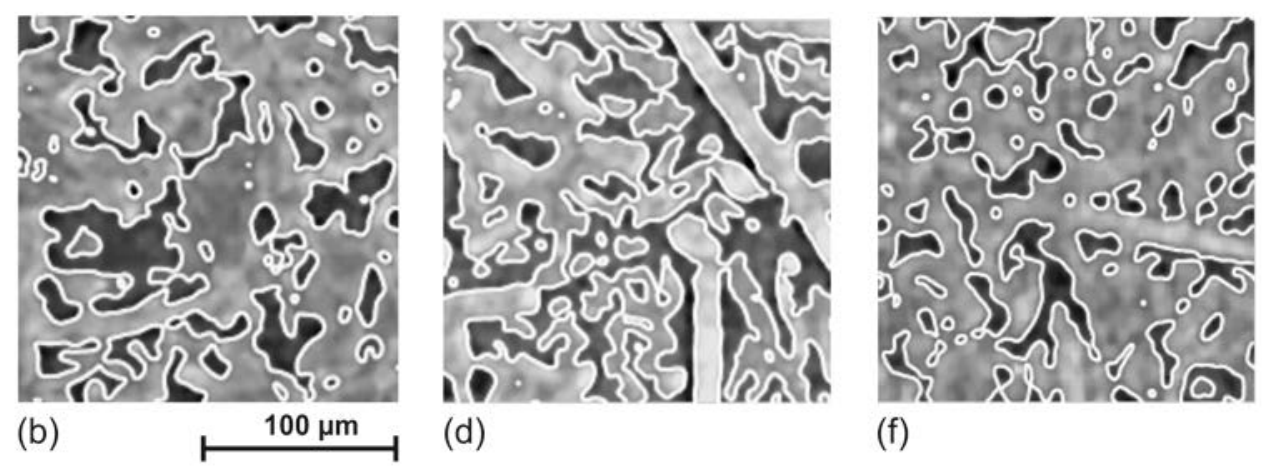

(d)

(f)

Figure 4. 3- and 2-dimensional images of ACBC materials in carbon configuration after pyrolysis. Pore channel system (colored in 3D) out of cross section area 1 from specimen C2 (a, b), E2 (c, d) and E7 (e, f).

Table III. Results of CT investigations obtained with corresponding CT evaluating software.

\begin{tabular}{|c|c|c|c|c|c|c|c|c|c|c|c|c|}
\hline \multirow{3}{*}{$\begin{array}{c}\text { Configuration } \\
\text { Specimen } \\
\text { cross section area }\end{array}$} & \multicolumn{6}{|c|}{ Green body } & \multicolumn{6}{|c|}{ Carbon preform } \\
\hline & \multicolumn{2}{|c|}{$\mathrm{C} 2$} & \multicolumn{2}{|c|}{ E2 } & \multicolumn{2}{|c|}{ E7 } & \multicolumn{2}{|c|}{$\mathrm{C} 2$} & \multicolumn{2}{|c|}{ E2 } & \multicolumn{2}{|c|}{ E7 } \\
\hline & 1 & 2 & 1 & 2 & 1 & 2 & 1 & 2 & 1 & 2 & 1 & 2 \\
\hline $\begin{array}{l}\text { Investigated volume } \\
\qquad \mathrm{V}\left[\mathrm{mm}^{3}\right]\end{array}$ & 0.8 & 0.8 & 0.8 & 0.8 & 0.8 & 0.8 & 0.8 & 0.8 & 0.8 & 0.8 & 0.8 & 0.8 \\
\hline $\begin{array}{c}\text { Open porosity } \\
\text { e' [\%] }\end{array}$ & 39.74 & 39.34 & 26.95 & 46.46 & 40.21 & 39.52 & 32.29 & 36.52 & 57.01 & 49.41 & 34.19 & 41.22 \\
\hline $\begin{array}{c}\text { Closed porosity } \\
\mathrm{e}_{\text {closed }}^{\prime}[\%]\end{array}$ & 0.14 & 0.19 & 2.8 & 0.04 & 0.04 & 0.03 & 0.26 & 0.15 & 0.04 & 0.04 & 0.08 & 0.13 \\
\hline $\begin{array}{c}\text { Foreign inclusions } \\
\qquad \mathrm{V}_{\mathrm{Fi}}[\%]\end{array}$ & 0.24 & 0.28 & 0.24 & 0.21 & 0.28 & 0.21 & 0.04 & 0.03 & 0.02 & 0.03 & 0.22 & 0.16 \\
\hline $\begin{array}{c}\text { Material volume } \\
\qquad \mathrm{V}_{\mathrm{M}}\left[\mathrm{mm}^{3}\right]\end{array}$ & 0.48 & 0.48 & 0.56 & 0.43 & 0.48 & 0.48 & 0.54 & 0.51 & 0.34 & 0.4 & 0.52 & 0.47 \\
\hline
\end{tabular}

Pore size distribution of CT-specimens out of cross section area 1 in green body as well as carbon preform configuration was measured by mercury intrusion porosimetry (table IV). All materials showed a homogenous pore size distribution in green body and carbon preform configuration. Significant peaks of modal pore diameter have always been present (fig. 5). For type ACBC C2 and E2 the modal diameter was $\sim 9 \mu \mathrm{m}$ in green body (fig. $5 \mathrm{a}, \mathrm{c}$ ) and between $7-10 \mu \mathrm{m}$ in carbon preform (fig. 5 b, d). Type ACBC E7 exhibits smaller pore sizes with a modal pore diameter of $\sim 5 \mu \mathrm{m}$ in green body and $\sim 4 \mu \mathrm{m}$ in carbon preform (fig. $5 \mathrm{e}, \mathrm{f}$ ). This trend has continued over measured pore surface and average pore diameter values (table IV). This fact is an indication for main influence of activated carbon grain size on pore size and pore size distribution. Comparing modal pore 
size in carbon stage with resulting SiSiC microstructure and density in cross section area 1 of material type E7 suggested that silicon infiltration and silicon carbide conversion for pore sizes of about $\sim 4 \mu \mathrm{m}$ is near optimum.

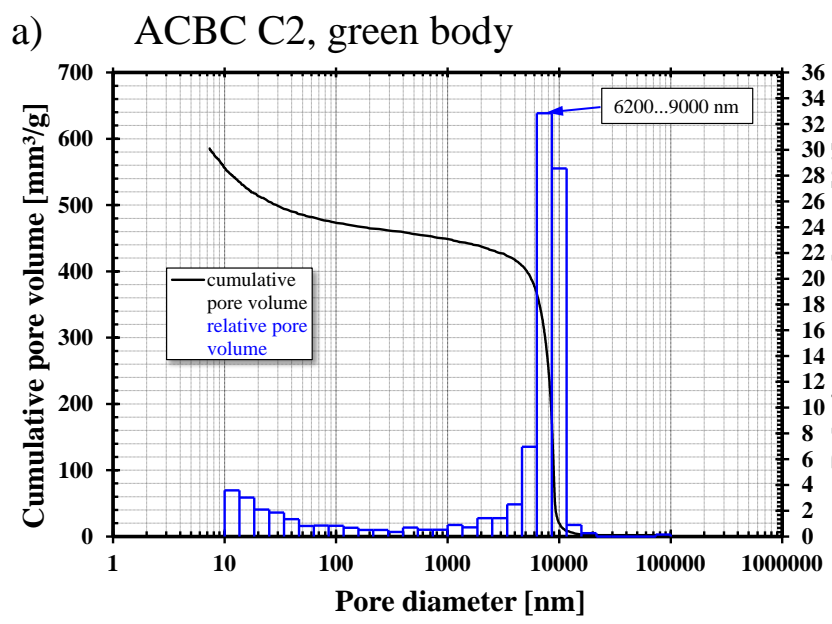

C

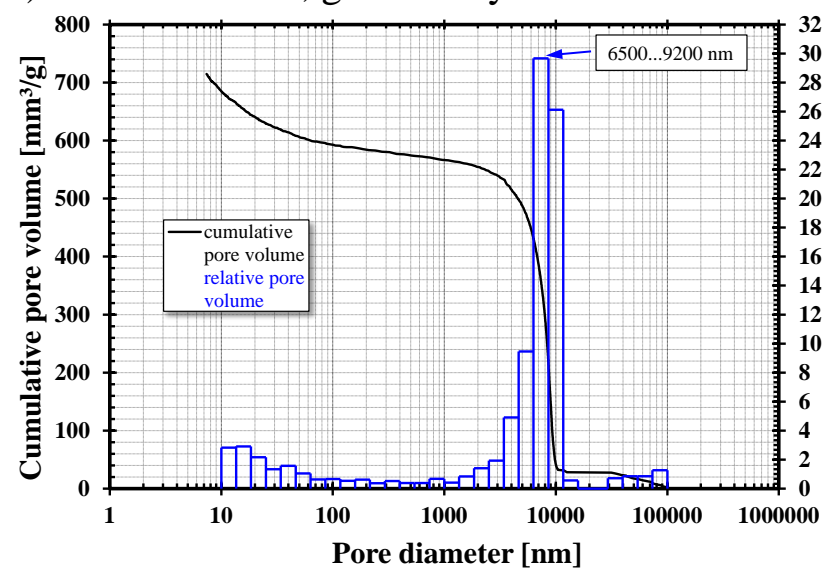

e)

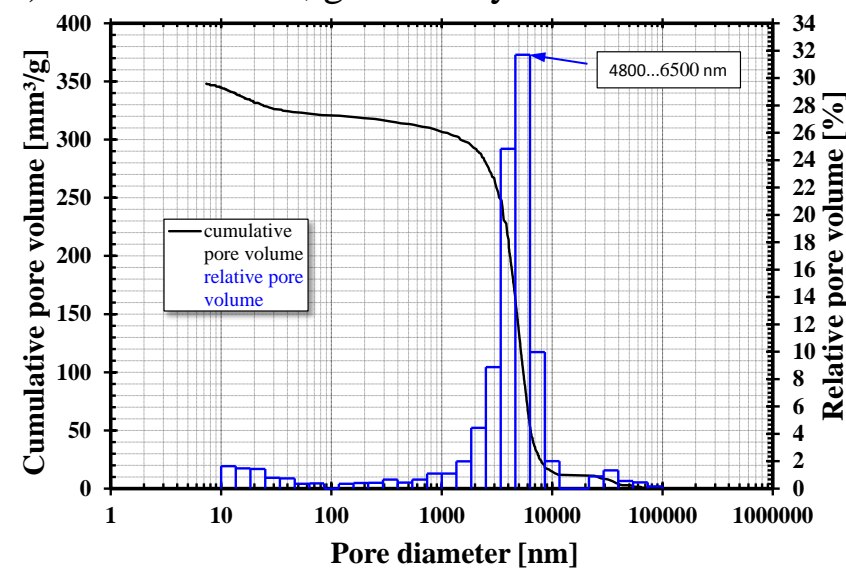

b) ACBC C2, carbon stage

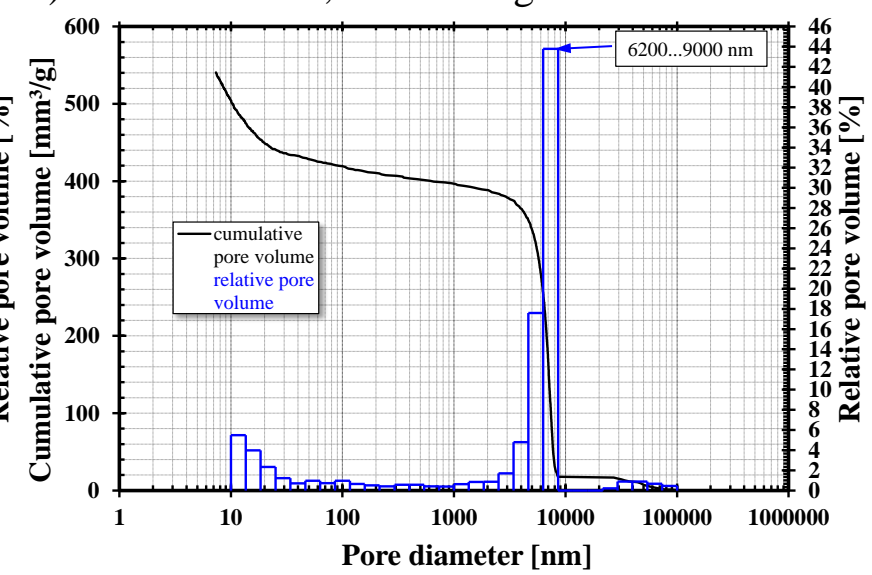

d) ACBC E2, carbon stage

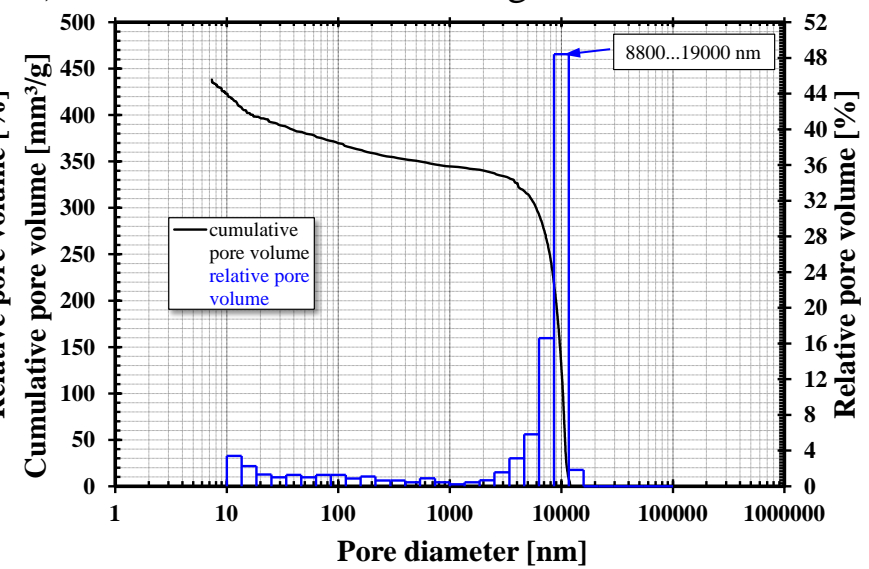

f) ACBC E7, carbon stage

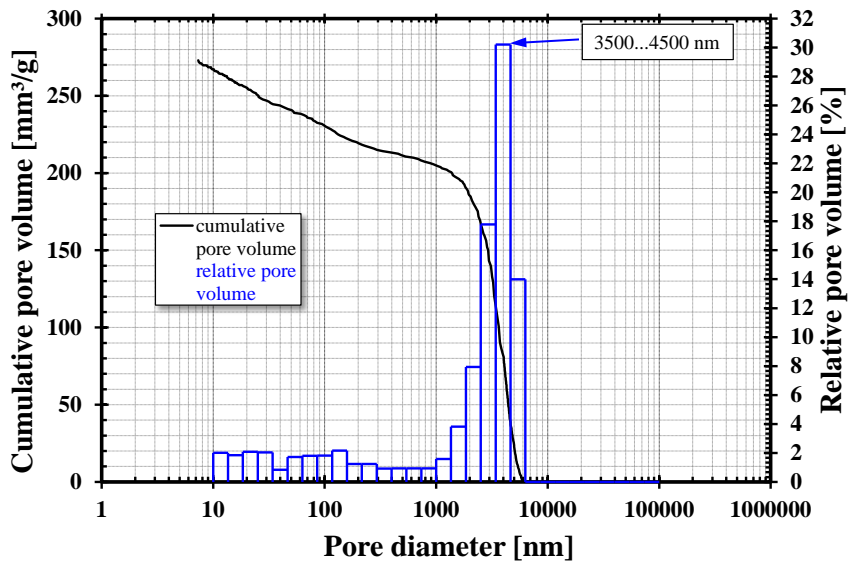

Figure 5. Pore size distribution in green body and carbon configuration of material ACBC C2 (a, b), ACBC E2 (c, d) and ACBC E7 (e, f). Highest peak represents the modal diameter range of each material type and configuration. 
Table IV. Pore size and pore surface volume measured by mercury intrusion porosimetry in green body and carbon preform configuration. Measured specimens were cut from cross section area 1 from curved structures.

\begin{tabular}{ccccc}
\hline \hline Material & Configuration & $\begin{array}{c}\text { Total pore volume } \\
{\left[\mathrm{mm}^{3} / \mathrm{g}\right]}\end{array}$ & $\begin{array}{c}\text { Total pore surface area } \\
{\left[\mathrm{m}^{2} / \mathrm{g}\right]}\end{array}$ & $\begin{array}{c}\text { Average pore diameter } \\
{[\mathrm{nm}]}\end{array}$ \\
\cline { 3 - 5 } & Green body & 585.46 & 31.65 & 73.99 \\
E2 & Green body & 715.05 & 33.44 & 85.53 \\
E7 & Green body & 348.08 & 7.02 & 198.43 \\
C2 & Carbon preform & 540.53 & 37.93 & 57.01 \\
E2 & Carbon preform & 438.13 & 18.69 & 93.79 \\
E7 & Carbon preform & 272.98 & 9.65 & 113.13 \\
\hline \hline
\end{tabular}

In curved parts which were processed by warm pressing density gradients occurred in the carbon stage which had a considerable impact on subsequent silicon carbide yield and SiC conversion during silicon infiltration. This was confirmed by scanning electron microscope images of siliconized curved specimens. For analysis specimens were cut out of 3 significant cross section areas. First of all, every type of material showed residual silicon content which was higher by a factor of 2 compared to the reference plates. Reason for this was the high open porosity of the curved carbon preforms (see fig. 3). Additionally, the silicon carbide-, residual silicon- and residual carbon contents were different within a material cross section. As example the density gradient in ACBC E7 is shown in fig. 6. Cross section 1 (was high dense in carbon preform, $0.90 \mathrm{~g} / \mathrm{cm}^{3}$ ) showed nearly the same $\mathrm{SiC}$ conversion degree as the middle section 2 (carbon preform density $=0.85 \mathrm{~g} / \mathrm{cm}^{3}$ ). The only difference between these cross section areas is the residual carbon content which is higher in section 1 (Fig. 6, E7-1 / E7-2). In total, the SiC conversion degree of $~ 70$ vol.\% was smaller than the conversion degree in reference plate ACBC E7 (81 vol.\%), although density and open porosity in carbon preform of reference plate and curved specimen were in good agreement. Thus, pore size and pore size distribution are very important for silicon carbide formation during infiltration of highly porous carbon. A homogenous SiC conversion degree in cross section of curved structures required an optimization of warm pressing technique.
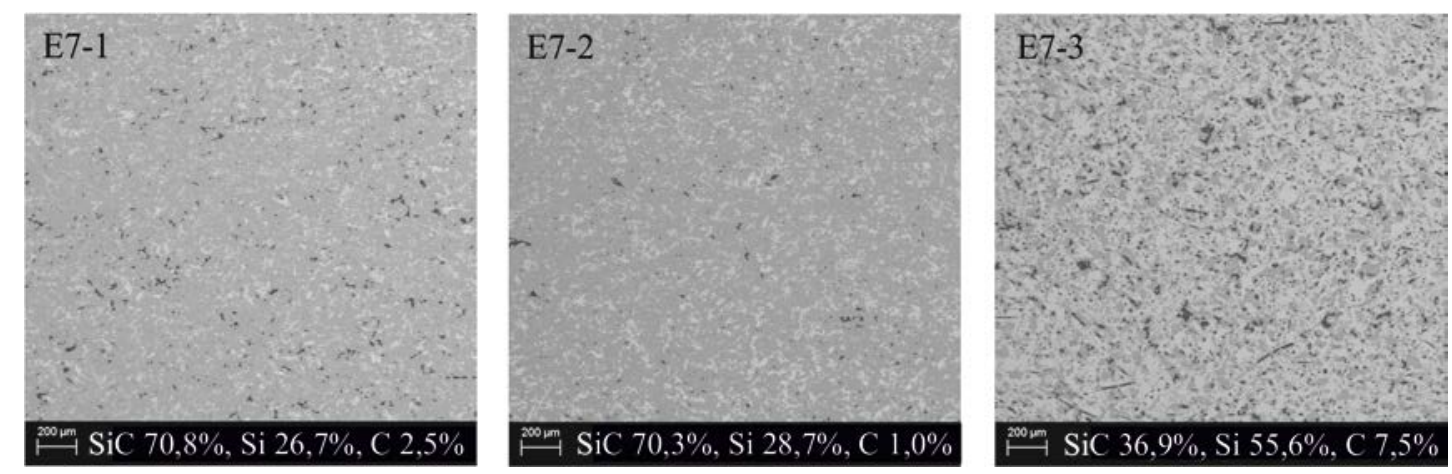

Figure 6. Microstructure configurations in cross section areas $(1-3)$ of curved specimen ACBC E7.

Shrinkage behavior

All materials showed differences in shrinkage behavior, depending on material composition. The estimated percentage values of geometry- and mass shrinkage are compared and listed in fig. 7 . The fiber doped materials, ACBC E2 and ACBC E7, were found to have the slightest shrinkage and showed their potential for net-shape manufacturing of SiSiC structures. The shrinkage of material type 
C2 was reduced by 50 \% compared to wood based material MDF. Because of its high shrinkage values and inflexibility in processing complex structures, material type MDF is not a candidate for net-shape manufacture under these processing conditions.

On macroscopic scale, there were no visible cracks on curved and plane sample surfaces of ACBC materials. This good shrinkage behavior indicates that complex shaped components can be produced using this composition.

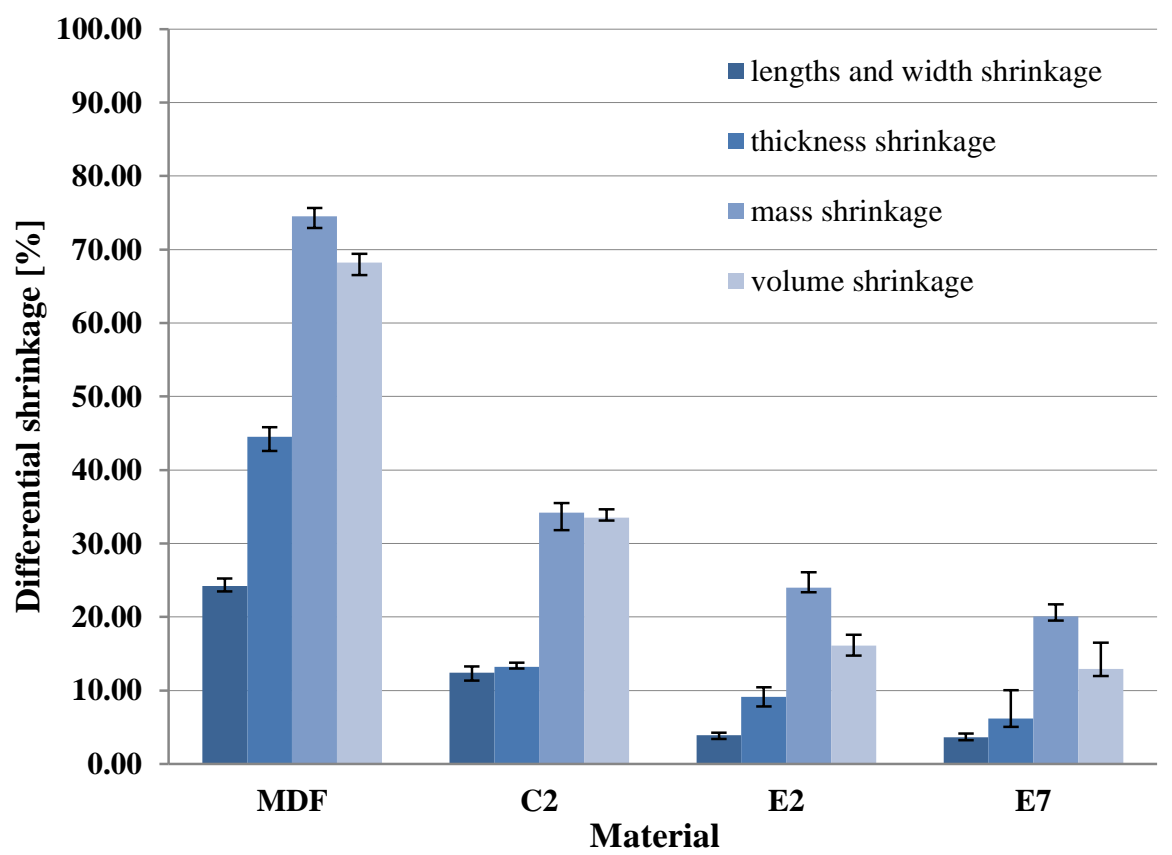

Figure 7. Shrinkage behavior during pyrolysis of wood fiber based material (MDF) and activated carbon based materials (C2, E2 and E7).

Physical properties

Table V summarizes the physical properties of the four investigated biomorphic SiSiC ceramics. Flexural strength, Young's modulus and hardness values increase with growing silicon carbide content. It was found that certain residual carbon content could be eradicated with simultaneous presence of high specific silicon carbide content. Images of typical fracture surfaces after four-point-bending test of each type of material are faced in fig. 8. These crack surfaces are a result of medium to high energy fracture behavior. The mean linear thermal expansion value differed only marginally for temperature range $20-1400^{\circ} \mathrm{C}$.

Table V. Physical properties of biomorphic inspired SiSiC materials.

\begin{tabular}{cccccc}
\hline \hline \multirow{2}{*}{ Material } & \multicolumn{5}{c}{ Physical properties } \\
\cline { 2 - 5 } & Density & Flexural strength & Young's modulus & Vickers hardness & $\begin{array}{c}\text { Mean linear } \\
\text { thermal expansion }\end{array}$ \\
& {$\left[\mathrm{g} / \mathrm{cm}^{3}\right]$} & {$[\mathrm{MPa}]$} & {$[\mathrm{GPa}]$} & $\mathrm{HV} 1[\mathrm{GPa}]$ & {$\left[10^{-6} \mathrm{~K}^{-1}\right]\left(20-1400 \mathrm{C}^{\circ}\right)$} \\
\cline { 2 - 6 } MDF & $2.77 \pm 0.01$ & $139 \pm 25$ & $243 \pm 23$ & $2014 \pm 364$ & $4.48 \pm 0.05$ \\
ACBC-C2 & $2.71 \pm 0.01$ & $156 \pm 24$ & $232 \pm 58$ & $2257 \pm 348$ & $4.45 \pm 0.05$ \\
ACBC-E2 & $2.96 \pm 0.01$ & $190 \pm 20$ & $287 \pm 34$ & $2395 \pm 222$ & $4.59 \pm 0.05$ \\
ACBC-E7 & $3.00 \pm 0.01$ & $201 \pm 21$ & $325 \pm 25$ & $2451 \pm 321$ & $4.52 \pm 0.05$ \\
\hline \hline
\end{tabular}



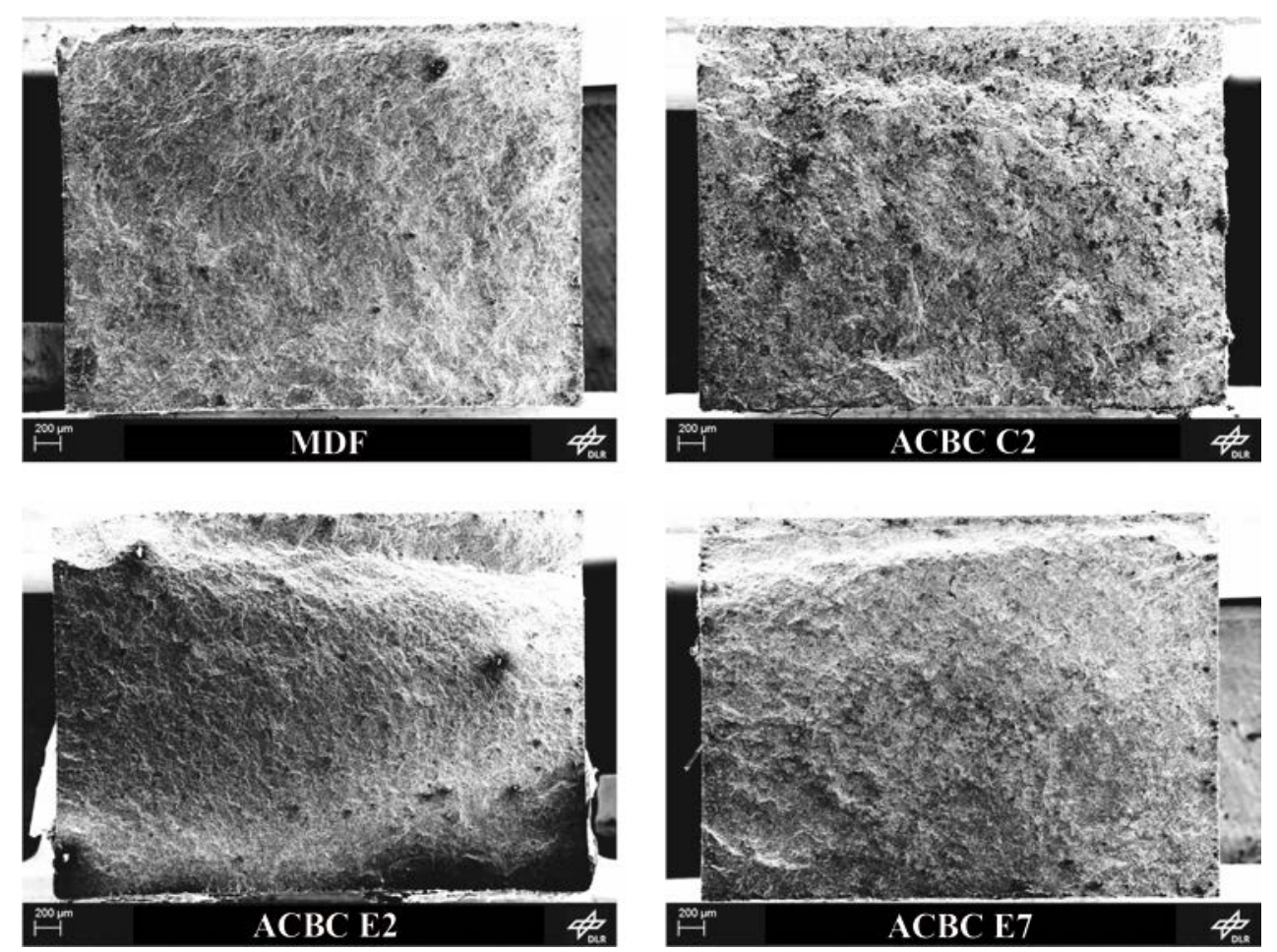

Figure 8. Typical crack surfaces of four-point-bending test specimens.

\section{CONCLUSION}

Three charcoal and one wood fiber based biomorphic SiSiC ceramics with different microstructures were successfully produced via LSI-technique. The critical shrinkage behavior of wood fiber based materials during processing could be reduced by over $50 \%$ by the use of charcoal based compounds. It could be shown that compounds based on activated carbon are promising candidates for structures with high silicon carbide content and complex forms.

First experiments of processing curved structures via warm pressing with ACBC compounds were conducted. Thereby, pore channel system in green body and carbon preform configuration could be investigated more closely. Furthermore it was possible to demonstrate the high impact of density gradient, transferred by warm pressing of curved structures, on pore size and pore size distribution and depending silicon carbide conversion. The focus for future work will be the processing of complex structures without density gradients and high silicon carbide contents.

Physical properties of investigated materials were determined. Silicon carbide content in microstructure is the most important factor for mechanical properties of SiSiC ceramics. However, the ratio between residual silicon and carbon is not as relevant in conjunction with significant silicon carbide presence.

\section{ACKNOWLEDGEMENT}

This research was supported by German Aerospace Center, Institute of Structures and Design, Stuttgart, Germany. The authors gratefully acknowledge Christoph Hillebrand and Jürgen Horvath (University of Bremen, Germany) for carrying out hardness measurements and Gudrun Steinhilber for conducting mercury intrusion porosimetry measurements.

\section{REFERENCES}

${ }^{1}$ S. Kumar, A. Kumar, A. Shukla, A.K. Gupta, R. Devi, Capillary infiltration studies of liquids into 3D-stitched C-C preforms: Part A: Internal pore characterization by solvent infiltration, mercury 
porosimetry, and permeability studies, Journal of the European Ceramic Society 29, 2643 - 2650, 2009.

${ }^{2}$ S. Kumar, A. Kumar, A. Shukla, A.K. Gupta, R. Devi, Capillary infiltration studies of liquids into 3D-stitched C-C preforms: Part B: Kinetics of silicon infiltration, Journal of the European Ceramic Society 29, 2651 - 2657, 2009.

${ }^{3}$ P. Greil, T. Lifka, A. Kaindl, Biomorphic Cellular Silicon Carbide Ceramics from Wood: I. Processing and Microstructure, Journal of the European Ceramic Society 18, 1961, 1998.

${ }^{4}$ D.-W. Shin, S.S Park, Y.-H. Choa, K. Niihara, Silicon / silicon carbide composites Fabricated byinfiltration of a silicon melt into charcoal, Journal of the American Ceramic Society 82, 3251-3254, 1999.

${ }^{5}$ T. Xue, Z.J.W. Wang, Preparation of porous SiC ceramics from waste cotton linter by reactive liquid Si infiltration technique, Materials Science and Engineering: A, 527, 7294 - 7298, 2010.

${ }^{6} \mathrm{M}$. Singh, D.R. Behrendt, Microstructure and mechanical properties of reaction-formed silicon carbide (RFSC) ceramics, Material Science and Engineering, 183-187, 1994.

${ }^{7}$ T.M. Lillo, D.W. Baily, D.A. Laughton, H.S. Chu, W.M. Harrison, Development of a pressureless sintered silicon carbide monolith and special-shaped silicon carbide whisker reinforced silicon carbide matrix composite for lightweight armor application, Ceramic engineering and science proceedings, 359-364, 2003.

${ }^{8}$ Y. Wang, S. Tan, D. Jiang, The effect of porous carbon preform and the infiltration process on the properties of reaction-formed SiC, Carbon 42, 1833 - 1839, 2004.

${ }^{9}$ L. Hozer, J.R. Lee, Y.M. Chiang, Reaction-infiltrated, net-shape SiC composites, Department of Materials Science and Engineering, 131-143, 1995.

${ }^{10} \mathrm{P}$. Greil, Near net shape manufacturing of ceramics, Materials Chemistry and Physics 61, 64-68, 1999.

${ }^{11}$ J. Qian, Z. Jin, Preparation and characterization of porous, biomorphic SiC ceramic with hybrid pore structure, Journal of the European Ceramic Society 26, 1311-1316, 2006.

${ }^{12}$ Y. Ikeda, M. Yasutoshi, M. Mizuno, M. Mukaida, M. Neo, T. Nakamura, 3 Dimensional CT analyses of bone formation in porous ceramic biomaterials, Ceramic engineering and science proceedings, 185-190, 2003. 